\title{
Performance Optimization Control of ECH using Fuzzy Inference Application*
}

\author{
Abhay Kumar DUBEY** \\ **NTPC Limited, Unchahar, Raebareli 229 406, India \\ E-mail: abhay_58117@rediffmail.com
}

\begin{abstract}
Electro-chemical honing $(\mathrm{ECH})$ is a hybrid electrolytic precision micro-finishing technology that, by combining physico-chemical actions of electro-chemical machining and conventional honing processes, provides the controlled functional surfaces-generation and fast material removal capabilities in a single operation. Process multi-performance optimization has become vital for utilizing full potential of manufacturing processes to meet the challenging requirements being placed on the surface quality, size, tolerances and production rate of engineering components in this globally competitive scenario. This paper presents an strategy that integrates the Taguchi matrix experimental design, analysis of variances and fuzzy inference system (FIS) to formulate a robust practical multi-performance optimization methodology for complex manufacturing processes like $\mathrm{ECH}$, which involve several control variables. Two methodologies one using a genetic algorithm tuning of FIS (GA-tuned FIS) and another using an adaptive network based fuzzy inference system (ANFIS) have been evaluated for a multi-performance optimization case study of ECH. The actual experimental results confirm their potential for a wide range of machining conditions employed in $\mathrm{ECH}$.
\end{abstract}

Key words: Electro-Chemical Honing, Taguchi Loss Function, Fuzzy Inference System, GA-Tuning, ANFIS, Analysis of Variances, Multi-Performance Optimization

\section{Introduction}

Electro-chemical honing $(\mathrm{ECH})$ is an electrolytic hybrid precision microfinishing technology that, by unique integration of physico-chemical actions of the electro-chemical machining and conventional honing processes, productively generates the functional surfaces that can be characterized by excellent surface quality and precisely controlled shape deviations ${ }^{(1)}$. ECH possesses a unique range of capabilities normally not achievable by either of the constituent processes: flexi-featured in controlling work surface characteristics; fast material removal; capability to correct form deviations and ability to improve work surface integrity (consequently, the service life of the component) ${ }^{(2)}$. Process is capable of providing surface roughness $R_{a}$ of order of $0.05 \mu \mathrm{m}$ and size tolerances within \pm 0.002 $\mathrm{mm}^{(3)}$. It can correct form deviations such as out-of-roundness, cylindricity, axis-distortion, taper, waviness, barrel and bell-mouth of workpiece the sizes of which are limited only by capability to supply current and electrolyte and practical limits of ECH tool size ${ }^{(4)}$. Part production rates could be as high as 5-10 times faster than the conventional honing ${ }^{(5)}$.

The process multi-performance optimization has become vital in the current globally competitive business scenario to utilize full potential of manufacturing process in meeting challenging requirements being placed on the surface quality, size, tolerances and production rate of components. Taguchi matrix experimental design allows process optimization with a minimum number of experiments while ensuring the process robustness 
against random variation. Taguchi technique can serve as an efficient tool for producing high quality products at low costs. Dubey ${ }^{(6)}$ has given a review of various methodologies adopted by researchers to utilize the Taguchi design, which was originally focused on single performance criteria, for solving multi-performance optimization problems. The hybrid neural networks $(\mathrm{NN})$-genetic algorithm (GA) strategies have also been recently reported for performance optimization of various advanced manufacturing processes such as electric discharge machining ${ }^{(7)}$, abrasive water jet cutting $^{(8)}$, electro-jet drilling process ${ }^{(9)}$, electro-chemical honing ${ }^{(10)}$. A critical evaluation of techniques utilized for the performance optimization of ECH reveals that hybrid NN-GA techniques, besides being computationally demanding, do not allow expert knowledge to be incorporated in decision-making process as in fuzzy inference system (FIS) ${ }^{(11)}$. Ostermark ${ }^{(12)}$ proposed a hybrid genetic fuzzy neural network (GFNN) for multi-group classification problems in which the genetic adaptation of membership functions to new data i.e. learning is reflected in the shape of the membership functions using evolutionary techniques combined with the fuzzy neural computations. Cheng et $\mathrm{al}^{(13)}$ used a multiple adaptive neuro-fuzzy inference system (MANFIS), an extension of a single output neuro-fuzzy inference system, to model the response surface of a chemical process and the resulting multiple objective decision making problem was optimized by a genetic algorithm. A fuzzy logic based Taguchi method was used by Lu and Antony $^{(14)}$ for a multi-response optimization case study. However, a limitation of using expert knowledge is the inability to tune an FIS to give precise outputs for several, possibly contradictory, input combinations.

In the present work, two integrated strategies based on Taguchi matrix experimental design and FIS: one using a genetic algorithm tuning of FIS and another using an adaptive network based fuzzy inference system (ANFIS) have been proposed to formulate a robust practical methodology of multi-performance optimization of ECH process. The use of GA for tuning the rule-base and membership functions enhances greatly the FIS performance. The utilization of neural network based training techniques in ANFIS allows FIS to learn the inherent intricacies of empirical data to make use of both expert and empirical information. The potential of proposed strategies has been evaluated using a multi-performance optimization case study of ECH for three dominant process performance criteria, the percent improvement in $\mathrm{R}_{\mathrm{a}}\left(\mathrm{PIR}_{\mathrm{a}}\right.$ ), percent improvement in cylindricity (PICyl) and diametral increase rate (DIR). The verification experiments confirm prospects of the proposed methodologies for a wide range of processing conditions employed in $\mathrm{ECH}$.

\section{Experimental}

Three elements of material processing: machine, tool, and workpiece are depicted in the ECH setup shown in Fig. 1. The setup consists of a power supply; an ECH tool and drives; electrolyte supply and cleaning system; and work holding and positioning system. A low DC potential of $3-30 \mathrm{~V}$ with current adjustable upto 200A is applied across the inter-electrode gap (IEG) between stainless steel cathode-tool body and anode-workpiece for the anodic dissolution. The ECH tool, which contains four auto-fed out non-conducting honing sticks, protruding from around the tool-circumference that are controlled by a light spring-mechanism, that is stroked through the work bore with a controlled generating motion of simultaneous rotation and reciprocation using speed controlled drives. Tool rotation is controlled using a variable speed DC servomotor and a microprocessor controlled programmable stepper-motor unit controls tool reciprocation. Honing sticks in ECH function to maintain a uniform tool-work gap and scrub the resulting electrolytic metal oxide microfilm preferentially from the higher spots and tight area in the work surface profile and thus make them highly receptive for EC attack. The lower areas still remaining covered with protective metal oxide microfilm receive weaker EC dissolution. The differential dissolution potential, thus created, is so potent in ECH that not only the surface finish but also the shape deviations are smoothed-off rapidly ${ }^{(15)}$. The spring stiffness and 
their initial compression can be adjusted to provide a desired stick-out pressure. A unique dual mode of electrolyte supply combining through-flushing and electrolyte supply to several locations in IEG through the holes drilled in cathode tool body ensures a uniform electrolytic condition in IEG. The electrolyte purity is ensured by double stage magnetic-cum-mechanical filtration employed at two crucial locations in electrolyte circuitry and settling. Worktable is designed with provisions of work loading; unloading; alignment and positioning; and ensuring work free-float condition during processing.

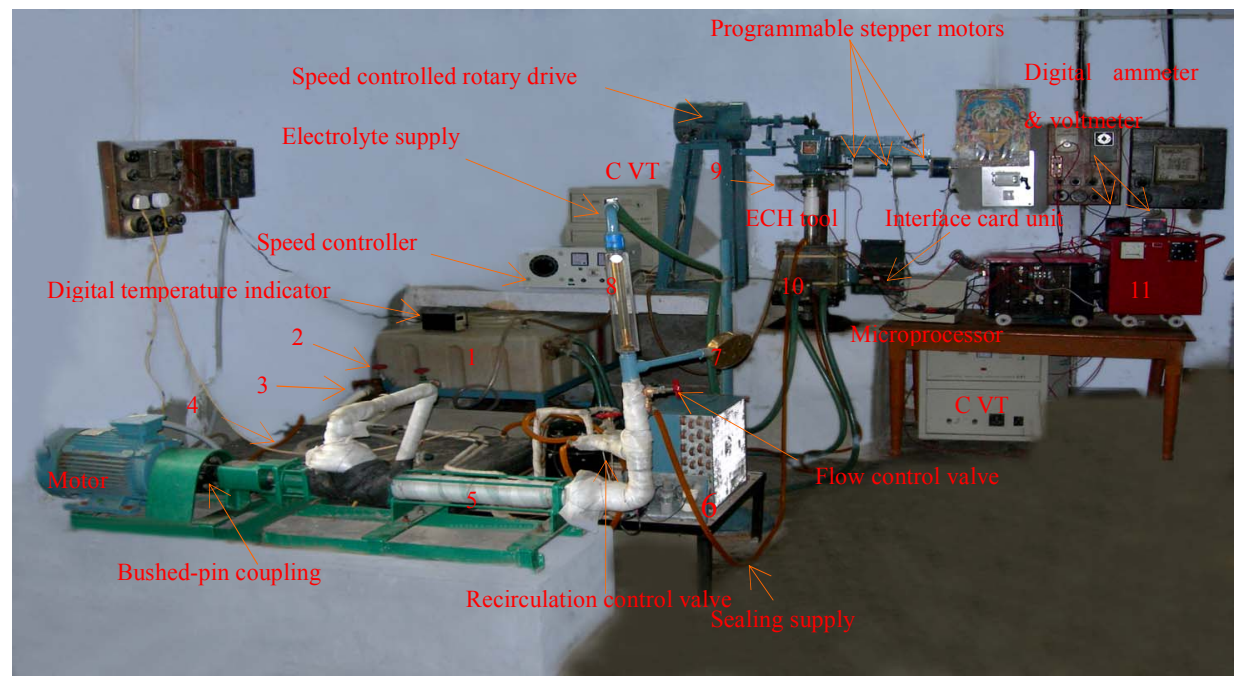

1) settling tank, 2) flow regulating valves, 3) 1st stage magnetic separator-cum-mechanical filter, 4) electrolyte storage tank, 5) electrolyte supply pump, 6) temperature control system, 7) pressure gauge, 8) flow meter, 9) copper-carbon brush-slip ring

assembly, 10) work chamber, 11) DC Power supply

Fig.1 Electro-chemical honing setup

Comprehensive experimentation was performed utilizing a standard $\mathrm{L}_{27}$ Taguchi matrix experimental design (Fig. 2) to establish parametric effects of seven key ECH input parameters (Table1): the current intensity, electrolyte concentration, rotary-to-reciprocating speed ratio, electrolyte flow rate, electrolyte inlet temperature to IEG, stick-out pressure and stick grit-size and three prospective two-factor interactions: C-EC, C-SR and EC-SR on dominant machining criteria: the percent improvement in surface roughness $R_{a}\left(P_{R}\right)$, percent improvement in cylindricity (PICyl) and diametral increase rate (DIR).

Table 1 Experimental domain

\begin{tabular}{|c|c|c|c|c|c|}
\hline \multicolumn{2}{|c|}{ ECH process parameters and responses } & \multirow[t]{2}{*}{ Symbol } & \multicolumn{3}{|c|}{ Levels } \\
\hline & & & $\mathrm{L}_{1}$ & $\mathrm{~L}_{2}$ & $\mathrm{~L}_{3}$ \\
\hline \multirow{7}{*}{$\begin{array}{l}\text { Input } \\
\text { parameters }\end{array}$} & Current intensity (A) & $\mathrm{C}$ & 50 & 115 & 180 \\
\hline & Electrolyte concentration $(\mathrm{g} / \mathrm{L})$ & EC & 100 & 150 & 200 \\
\hline & Rotary-to-reciprocating speed ratio & SR & 50 & 150 & 250 \\
\hline & Electrolyte flow rate (lpm) & $\mathrm{F}$ & 10 & 20 & 30 \\
\hline & Electrolyte inlet temperature $\left({ }^{\circ} \mathrm{C}\right)$ & $\mathrm{T}$ & 10 & 30 & 50 \\
\hline & Stick-out pressure $(\mathrm{kPa})$ & SOP & 10 & 20 & 30 \\
\hline & Stick grit size & $\mathrm{G}$ & 360 & 600 & 1200 \\
\hline $\begin{array}{l}\text { Performance } \\
\text { characteristics }\end{array}$ & $\begin{array}{l}\text { Percent improvement in } R_{a} \\
\text { Percent improvement in cylindricity } \\
\text { Diametral increase rate }(\mu \mathrm{m} / \mathrm{min})\end{array}$ & $\begin{array}{c}\mathrm{PIR}_{\mathrm{a}} \\
\mathrm{PICyl} \\
\mathrm{DIR}\end{array}$ & & & \\
\hline $\begin{array}{l}\text { Fixed } \\
\text { parameters }\end{array}$ & $\begin{array}{l}\text { Reciprocating speed: } 0.4 \text { smpm; Pro } \\
\text { mm; Electrolyte composition (by we } \\
\text { Type of abrasive: SiC; Mode of proc } \\
\text { ASTM } 35 \text { cylindrical block. }\end{array}$ & $\begin{array}{l}\text { ssing tim } \\
\text { htt): } 3 / 4 \mathrm{pa} \\
\text { s operatic }\end{array}$ & $\begin{array}{l}\mathrm{O0s} ; \\
\mathrm{TaCl} \\
\mathrm{ECH}\end{array}$ & $\begin{array}{l}\text { itial I } \\
1 / 4 \text { par } \\
\text { Vork }\end{array}$ & $\begin{array}{l}0.5 \\
\mathrm{TaNO}_{3} ; \\
\text { cimen: }\end{array}$ \\
\hline
\end{tabular}




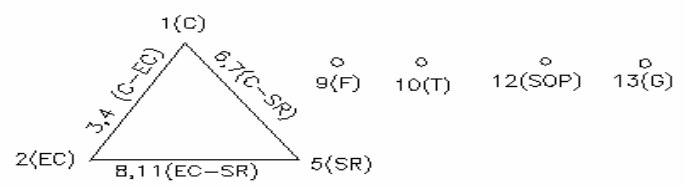

Fig. $2 \mathrm{~L}_{27}$ linear graph for parameter assignment to $\mathrm{OA}$

The experimental trials were repeated twice in a random order sequence in order to minimize the time error variability, if any. Work surface roughness $R_{a}$ prior to and after ECH was measured by using a Mahr Perthometer 4615 set with a cut-off length of $0.8 \mathrm{~mm}$. Five measurements at top, middle and bottom of work-bore were taken separately perpendicular to the lay and the average value used. Work-bore diameter was separately measured at top, middle and bottom on a 3D CMM (MOUSER KMZ 201210, ZEISS, Germany) interfaced with UMESS 300 software considering at least 400 points in scanning mode and the average value utilized. A minimum 16 points on work-bore were taken on 3D CMM to measure work-bore cylindricity. Improvements expressed as the percentage of initial values of respective performance characteristics were taken so as to negate the effect of initial variation, if any.

\section{Fuzzy Inference System}

A fuzzy inference system can very effectively model the complex uncertain real world problems by incorporating qualitative aspects of human knowledge and reasoning process, without employing a precise quantitative analysis. The fuzzy set ${ }^{(16 \text { and } 17)}$ supports a flexible sort of membership of the elements to a set as against the crisp set and thus, a membership function is associated with it that maps every element of the universe of discourse to the interval $(0,1)$. The FIS uses the process knowledge in form of fuzzy logic rules and membership functions, which are often gathered from the experimental experience, to approximate the expert perception and judgment in modeling the process input-output relationship using linguistic variables rather than a complicated dynamic model ${ }^{(18)}$. An FIS consists of five functional blocks (Fig. 3a) ${ }^{(19)}$. The rule base contains a number of fuzzy if-then rules or fuzzy conditional statements of the form IF A THEN B (where A and B are labels of fuzzy sets) formulated on the basis of process knowledge. A database defines membership functions of the fuzzy sets. Triangular, trapezoidal and Gaussian membership functions are commonly used. The rule-base and the database are jointly referred to as the knowledge base. The fuzzy inference engine performs inference operations on the logic rules using operators within the rules. Generally logic rules use AND (maximum value) or OR (minimum value) as connecting operators. The fuzzification interface transforms the crisp inputs into degrees of match with linguistic values and a defuzzification interface converts the fuzzy inference results into crisp output. Centroid (center of gravity or center of area); center of sums; and mean of maxima methods are commonly employed for defuzzification. A Mamdani's FIS ${ }^{(20 \text { and } 21)}$ was used with GA-tuned FIS in the present investigation.

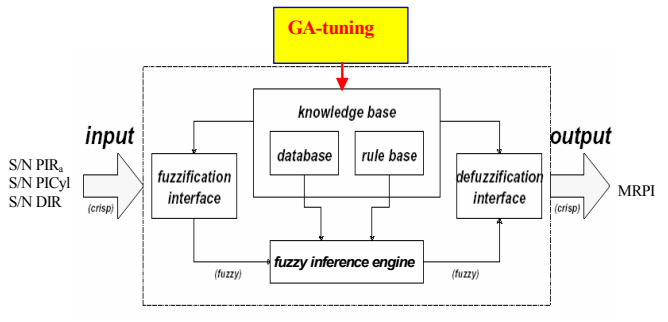

a) Structure of a GA-tuned FIS

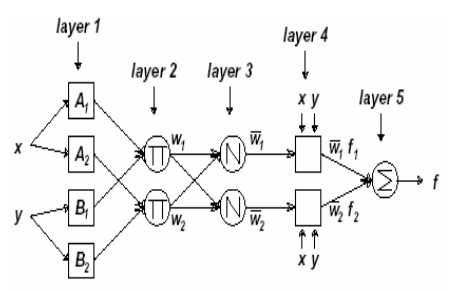

b) ANFIS architecture

Fig. 3 A fuzzy inference system

It is important to realize that the performance of an FIS is largely dependent upon the 
accuracy of the formulated knowledge base and here, arises the need for effective tuning of membership functions and rule base to minimize the FIS output error or maximize its performance index. GAs have been intensively utilized in the recent years for rule base

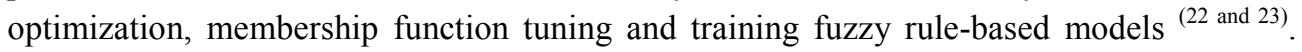
Since GA is also computationally demanding, FIS tuning is generally done offline.

\subsection{Adaptive-Network-Based Fuzzy Inference System}

An ANFIS can learn intricacies inherent in the empirical data to make use of both expert and empirical information to generate the stipulated input-output pairs. ANFIS makes use of a hybrid-learning rule to optimize the FIS parameters of a first order Sugeno system (Fig. $3 b)^{(19 \text { and } 24) .}$ For simplicity, if we assume that FIS has two inputs $x$ and $y$ and one output $f$ and the rule base consists of two fuzzy if-then rules of Takagi and Sugeno's type:

Rule1: If $x$ is $A_{1}$ and $y$ is $B_{1}$, then $f_{1}=p_{1} x+q_{1} y+r_{1}$

Rule2: If $x$ is $A_{2}$ and $y$ is $B_{2}$, then $f_{2}=p_{2} x+q_{2} y+r_{2}$

where $p, q, r$ are the consequent parameters of the rules, which contribute through a first order polynomial. The ANFIS architecture consists of five layers with output of $i^{\text {th }}$ node of layerl represented by ${ }_{O} \quad \begin{aligned} & 1 \\ & i\end{aligned}$ and two trainable parameter sets: the antecedent membership function parameters $(a, b, c)$ and polynomial consequent parameters $(p, q, r)$. ANFIS training paradigm utilizes a hybrid learning rule: a gradient descent algorithm to optimize the antecedent parameters and a least square algorithm to solve for the consequent parameters.

Layer1: Generates membership grades: consists of square nodes with membership function $\mathrm{O}_{\mathrm{i}}^{1}=\mu_{\mathrm{A}} \mathrm{i}(\mathrm{x})$, where $A i$ is the linguistic label associated with $\mathrm{i}^{\text {th }}$ node function. For a Guassian membership function,

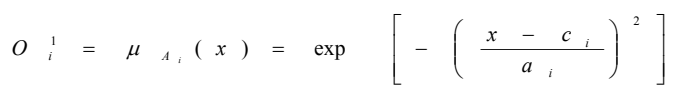

where $a_{i}, c_{i}$ is the parameter set known as premise parameters. As the values of these parameters change, bell-shaped functions vary accordingly, thus exhibiting various forms of membership function on $A_{i}$.

Layer2: Generates firing strengths: the circle nodes in this layer multiply incoming signal and send the product output, $\mathrm{O}_{\mathrm{i}}^{2}=\mathrm{w}_{\mathrm{i}}=\Pi_{\mathrm{j}=1}^{\mathrm{m}} \mu_{\mathrm{A}} \mathrm{i}(\mathrm{x})$. Each node output is the firing strength of a rule.

Layer3: Normalizes the firing strengths:

$\mathrm{O}_{\mathrm{i}}^{3}=\overline{\mathrm{w}} \mathrm{i}=\frac{\mathrm{w}_{\mathrm{i}}}{\mathrm{w} 1+\mathrm{w}_{2}}$

Layer4: Calculates rule outputs based on consequent parameters:

$\mathrm{O}_{\mathrm{i}}^{4}=\mathrm{y}_{\mathrm{i}}=\overline{\mathrm{wi}_{\mathrm{i}}} \mathrm{i}_{\mathrm{i}}=\overline{\mathrm{wi}_{\mathrm{i}}}\left(\mathrm{p}_{\mathrm{i}} \mathrm{x}_{\mathrm{i}}+\mathrm{qi}_{\mathrm{i}}+\mathrm{r}_{\mathrm{i}}\right)$

Layer5: Sums all the inputs from layer4:

$\mathrm{O}_{\mathrm{i}}^{5}=\sum_{\mathrm{i}} \mathrm{y} \mathrm{i}^{5}=\sum_{\mathrm{i}} \overline{\mathrm{w}_{\mathrm{i}}} \mathrm{f}_{\mathrm{i}}$ 4. Performance Optimization Control of ECH using Fuzzy Inference
Application

\subsection{FIS Modeling of ECH}

Taguchi loss function can serve as an efficient optimization tool in case of single 
performance characteristic. But for multi-performance optimization an overall evaluation of the signal-to-noise ratio ( $\mathrm{S} / \mathrm{N}$ ratio) is required, as a higher value of $\mathrm{S} / \mathrm{N}$ ratio for one performance characteristic may correspond to a lower one for another. The use of an FIS can provides an effective solution to the problem. The designed ECHFIS (Fig. 3a) fuzzifies the loss functions of multiple process performance characteristics and uses the max-min fuzzy inference and centroid defuzzification method to obtain a single fuzzy reasoning grade called multi-response performance index (MRPI) ${ }^{(25)}$. As given in Table 2, the control variables were fuzzified using four equally spaced bell-shaped membership functions selected conventionally, while seven equally spaced Gaussian curves were utilized for fuzzification of the action variable (MRPI) for better visibility. The universe of discourse for variables were decided based on the analysis of available experimental data. Linguistic terms used for input variable membership functions are low (L), medium (M), high (H) and very high (VH) and for output variable are very low (VL), low (L), low small (LS), medium (M), high small (HS), high (H) and very high (VH). In the present case since there are three input variables each with four membership functions, hence total number of rules initially formulated on the basis of experimental knowledge of ECH process were $4^{3}$ i.e. 64. Finally, the fuzzy output of all the fuzzy rules for given input values is processed and converted back into a crisp value.

Table 2 Membership functions

\begin{tabular}{|c|c|c|c|c|c|c|c|}
\hline \multirow[t]{2}{*}{ Control variables } & \multicolumn{7}{|c|}{ Membership functions (initial) } \\
\hline & \multicolumn{2}{|c|}{$\mathrm{L}$} & \multicolumn{2}{|c|}{ M } & \multicolumn{2}{|c|}{$\mathrm{H}$} & VH \\
\hline $\mathrm{PIR}_{\mathrm{a}}$ & \multicolumn{2}{|c|}{35.80} & \multicolumn{2}{|c|}{36.81} & \multicolumn{2}{|c|}{37.82} & 38.83 \\
\hline PICyl & \multicolumn{2}{|c|}{26.75} & \multicolumn{2}{|c|}{30.41} & \multicolumn{2}{|c|}{34.07} & 37.73 \\
\hline DIR & \multicolumn{2}{|c|}{16.80} & \multicolumn{2}{|c|}{22.93} & \multicolumn{2}{|c|}{29.07} & 35.20 \\
\hline Response variable & VL & $\mathrm{L}$ & LS & $\mathrm{M}$ & HS & $\mathrm{H}$ & VH \\
\hline MRPI & 0.00 & 0.17 & 0.33 & 0.50 & 0.67 & 0.83 & 1.00 \\
\hline
\end{tabular}

\subsection{GA-tuning of ECHFIS}

The complete set of all possible fuzzy rules and all membership function sets were considered initially as a solution space to optimize both the membership functions and the rule base of the FIS using GA.

Database tuning: positions of minimum fuzziness points of bell-shaped functions are varied in both directions by one-third of their base width. GA optimization is performed considering the minimum fuzziness point as the main variable represented by a nine-bit binary string with crossover and mutation probabilities of 0.95 and 0.05 respectively, population size 100 and roulette wheel parent selection criterion, where strings are multiplied depending on their fitness values and placed in the mating pool. Rule base is prepared and FIS is realized by writing a program in MATLAB environment with 'Mamdani System Version 2'. The FIS output for known input values is compared with that of experimental output. If error obtained is not within accepted tolerances of 0.0001 , the initial strings of tuning variables are processed and iterations are performed with GA operators like reproduction, crossover and mutation until the stopping criterion is met as given in flow chart Fig. 4. The optimal GA-tuned membership functions of ECHFIS are given in Fig. 5. These membership functions truly represent the respective variable's behavior and hence, are considered for further FIS evaluation and prediction of outputs.

Rulebase tuning: A binary string of 64 bits matching with the number of FIS rules is used for rule-base optimization. The binary string is generated at random initially and a rule is included if the matching bit is one and discarded if the bit is zero. Out of 64 fuzzy rules only 17 rules were considered after tuning (Table 3 ). Rest 47 rules were discarded. 


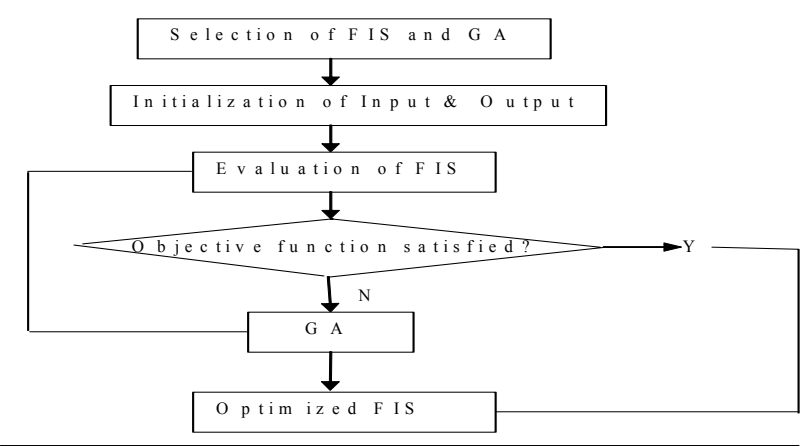

Fig. 4 Flow chart for optimization of FIS using GA

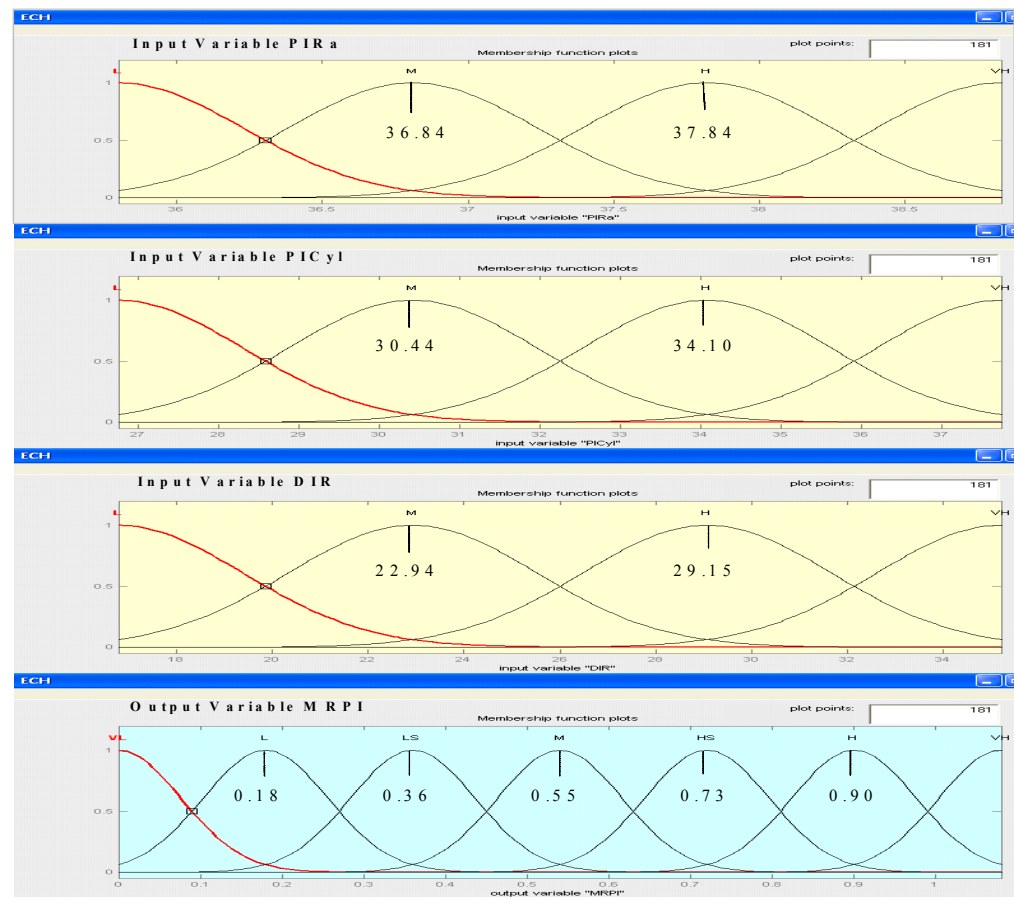

Fig. 5 GA-tuned membership functions of ECHFIS

\begin{tabular}{lllll}
\multicolumn{5}{c}{ Table 3 GA optimized rule-base of ECH FIS } \\
\hline S1. no. & PIR $_{\mathrm{a}}$ & PICyl & DIR & MRPI \\
\hline 1 & $\mathrm{~L}$ & $\mathrm{H}$ & $\mathrm{M}$ & $\mathrm{M}$ \\
2 & $\mathrm{M}$ & $\mathrm{H}$ & $\mathrm{M}$ & $\mathrm{HS}$ \\
3 & $\mathrm{M}$ & $\mathrm{VH}$ & $\mathrm{M}$ & $\mathrm{HS}$ \\
4 & $\mathrm{H}$ & $\mathrm{H}$ & $\mathrm{M}$ & $\mathrm{HS}$ \\
5 & $\mathrm{M}$ & $\mathrm{VH}$ & $\mathrm{M}$ & $\mathrm{HS}$ \\
6 & $\mathrm{M}$ & $\mathrm{M}$ & $\mathrm{M}$ & $\mathrm{M}$ \\
7 & $\mathrm{M}$ & $\mathrm{VH}$ & $\mathrm{H}$ & $\mathrm{H}$ \\
8 & $\mathrm{H}$ & $\mathrm{H}$ & $\mathrm{H}$ & $\mathrm{H}$ \\
9 & $\mathrm{H}$ & $\mathrm{VH}$ & $\mathrm{H}$ & $\mathrm{H}$ \\
10 & $\mathrm{M}$ & $\mathrm{L}$ & $\mathrm{M}$ & $\mathrm{LS}$ \\
11 & $\mathrm{VH}$ & $\mathrm{H}$ & $\mathrm{VH}$ & $\mathrm{VH}$ \\
12 & $\mathrm{M}$ & $\mathrm{M}$ & $\mathrm{L}$ & $\mathrm{M}$ \\
13 & $\mathrm{H}$ & $\mathrm{H}$ & $\mathrm{VH}$ & $\mathrm{H}$ \\
14 & $\mathrm{H}$ & $\mathrm{M}$ & $\mathrm{H}$ & $\mathrm{HS}$ \\
15 & $\mathrm{H}$ & $\mathrm{VH}$ & $\mathrm{VH}$ & $\mathrm{VH}$ \\
16 & $\mathrm{M}$ & $\mathrm{H}$ & $\mathrm{H}$ & $\mathrm{HS}$ \\
17 & $\mathrm{VH}$ & $\mathrm{VH}$ & $\mathrm{VH}$ & $\mathrm{VH}$ \\
\hline
\end{tabular}

Fitness evaluation: for GA-based optimization, 27 sets of input parameter values 


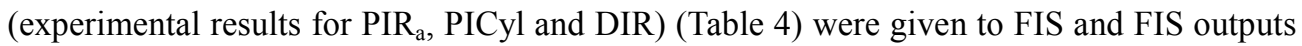
were compared with the actual outputs from the experiments. The average of the absolute error for these twenty seven cases was taken as the fitness function for genetic algorithm. GA was used with different sets of its parameters but there was no significant improvement in the performance of the optimized FIS and hence parameter set of GA was accepted where crossover and mutation probabilities were 0.95 and 0.05 respectively and the population size was 100 strings. The MRPI results of GA-tuned FIS of ECH are given in Table 4.

Table 4 FIS modeling results ( PIR $_{\mathrm{a}}$-PICyl-DIR)

\begin{tabular}{|c|c|c|c|c|c|}
\hline $\begin{array}{l}\text { Trial } \\
\text { no. }\end{array}$ & $\begin{array}{l}\mathrm{PIR}_{\mathrm{a}} \\
(\mathrm{dB})\end{array}$ & $\begin{array}{l}\text { PICyl } \\
(\mathrm{dB})\end{array}$ & $\mathrm{DIR}(\mathrm{dB})$ & $\begin{array}{c}\text { MRPI } \\
\text { (GA-tuned FIS) }\end{array}$ & $\begin{array}{c}\text { MRPI } \\
\text { (ANFIS) }\end{array}$ \\
\hline 1 & 35.80 & 32.11 & 21.80 & 0.564 & 0.500 \\
\hline 2 & 36.39 & 34.63 & 23.16 & 0.664 & 0.487 \\
\hline 3 & 36.65 & 34.57 & 20.89 & 0.691 & 0.605 \\
\hline 4 & 36.70 & 32.28 & 23.57 & 0.644 & 0.610 \\
\hline 5 & 36.64 & 32.92 & 24.77 & 0.668 & 0.620 \\
\hline 6 & 37.34 & 37.31 & 21.32 & 0.722 & 0.695 \\
\hline 7 & 38.24 & 35.42 & 22.85 & 0.734 & 0.700 \\
\hline 8 & 37.16 & 33.75 & 21.46 & 0.692 & 0.610 \\
\hline 9 & 37.88 & 26.75 & 25.13 & 0.534 & 0.485 \\
\hline 10 & 36.00 & 33.05 & 21.92 & 0.586 & 0.490 \\
\hline 11 & 37.21 & 33.29 & 23.67 & 0.702 & 0.600 \\
\hline 12 & 36.57 & 34.30 & 22.42 & 0.682 & 0.595 \\
\hline 13 & 36.77 & 30.49 & 21.66 & 0.549 & 0.500 \\
\hline 14 & 36.72 & 36.27 & 26.69 & 0.792 & 0.725 \\
\hline 15 & 37.54 & 33.86 & 28.73 & 0.820 & 0.745 \\
\hline 16 & 38.09 & 35.05 & 27.97 & 0.858 & 0.750 \\
\hline 17 & 38.04 & 36.37 & 30.60 & 0.898 & 0.850 \\
\hline 18 & 36.91 & 27.11 & 21.82 & 0.897 & 0.405 \\
\hline 19 & 38.39 & 32.80 & 32.27 & 0.851 & 0.900 \\
\hline 20 & 36.89 & 28.23 & 16.80 & 0.514 & 0.455 \\
\hline 21 & 38.02 & 34.54 & 35.20 & 0.892 & 0.800 \\
\hline 22 & 37.86 & 29.69 & 29.83 & 0.701 & 0.620 \\
\hline 23 & 37.37 & 37.21 & 33.32 & 0.901 & 0.925 \\
\hline 24 & 36.43 & 30.65 & 30.10 & 0.658 & 0.650 \\
\hline 25 & 37.40 & 33.85 & 26.60 & 0.796 & 0.755 \\
\hline 26 & 38.21 & 36.05 & 33.51 & 0.927 & 0.935 \\
\hline 27 & 38.83 & 37.73 & 35.13 & 0.998 & 1.000 \\
\hline
\end{tabular}

\subsection{ANFIS Modeling of ECH}

The ANFIS modeling of ECH for the present case study was done using a 'Sugeno System Version 2' in MATLAB environment using all the 64 fuzzy rules formulated and membership functions given in Table 2. The optimal ANFIS membership functions of ECH FIS are given in Fig. 6.

\section{Analysis and Discussion of Results}

The control surfaces generated by GA-tuned FIS and ANFIS are given in Fig. 7 and 8 respectively. These control surface plots provide combined effect of two control parameters on the ECH FIS output and can be utilized to predict the MRPI of FIS. The outputs (MRPI) of the GA-tuned FIS and ANFIS for 27 experimental trial conditions (Table 4) were analyzed as per the standard procedure ${ }^{(26}$ and 27$)$ using analysis of means (ANOM), analysis of variances (ANOVA) and $\mathrm{F}$ ratio to identify the significant parameters, quantify their 
effects on MRPI, select optimal process parametric settings and estimate optimal value of MRPI obtainable within the experimental domain.

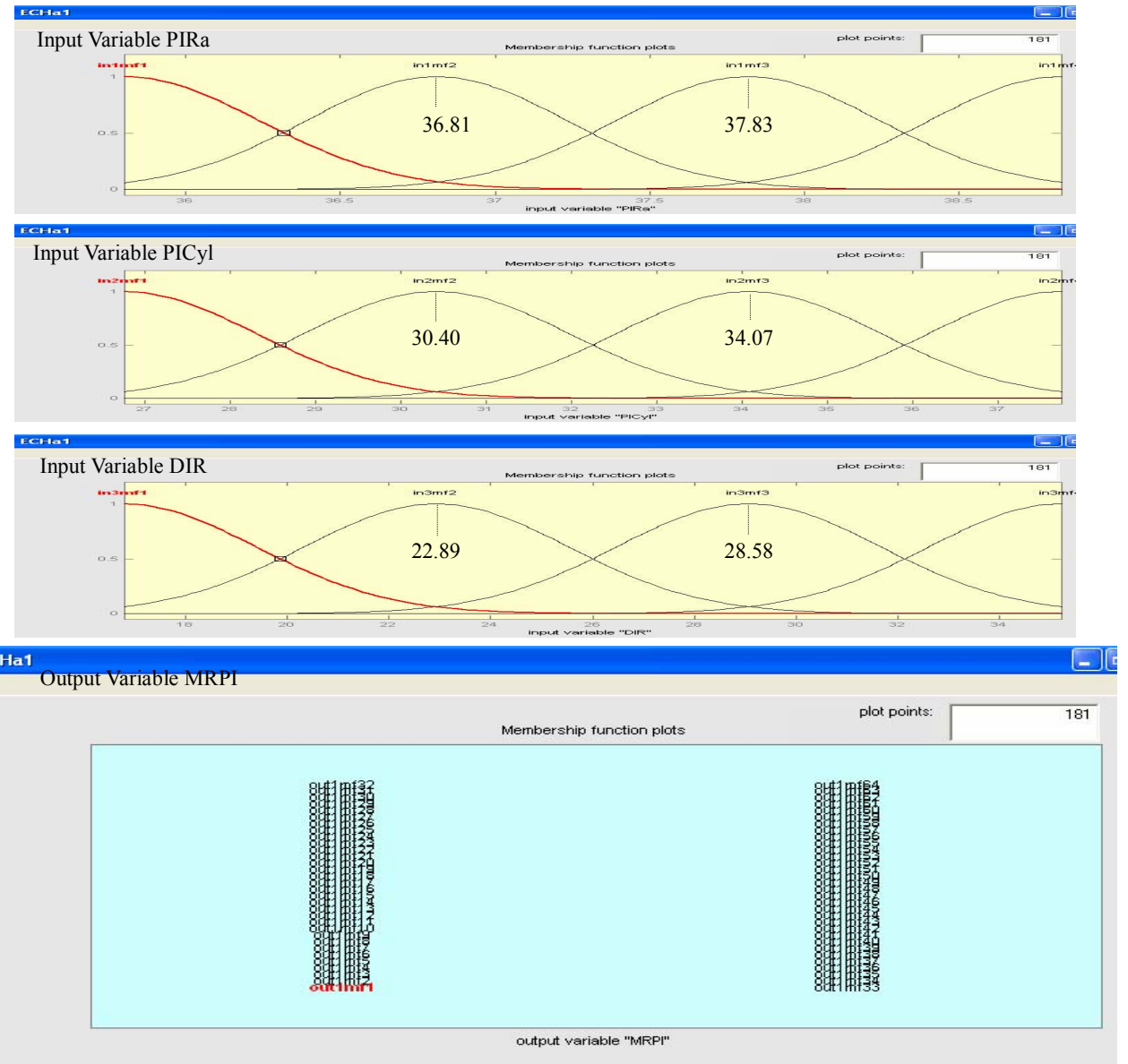

Fig. 6 ANFIS membership functions of ECH

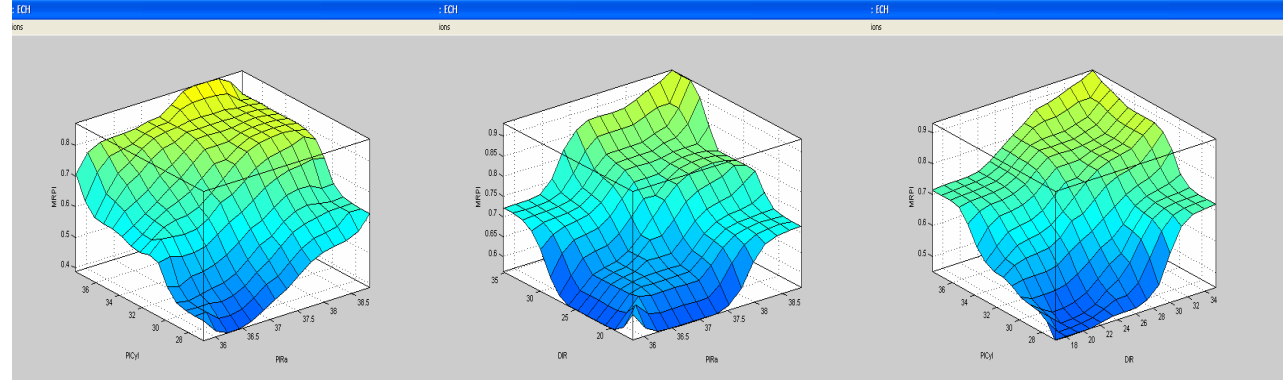

Fig. 7 Control surfaces generated by GA-tuned FIS

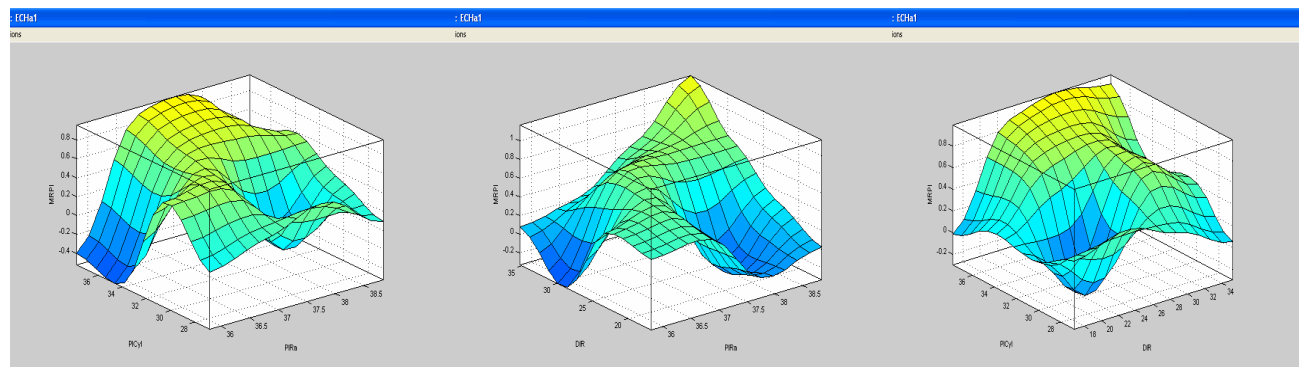

Fig. 8 Control surfaces generated by ANFIS

The ANOVA results for MRPI are given in Table 5. The results for GA-tuned FIS indicate that the current intensity, electrolyte concentration, rotary-to-reciprocating speed ratio, stick-out pressure, and stick grit-size and all the three interactive terms, namely the 
current intensity-electrolyte concentration, current intensity-speed ratio and electrolyte concentration-speed ratio are significant for MRPI a confidence level of $95 \%$. Pooling of insignificant effects is done in order to obtain a better reliability of conclusions. Based on the relative percent contribution of the significant parameters for MRPI it is seen that $\mathrm{C}$, EC, SOP, G and EC-SR are the major contributors for MRPI in ECH. Quite similar results are also observed in ANFIS, except for SR, which is found not significant at the $95 \%$ confidence level. However, it can be seen that independent effect of speed ratio is very less in the case of GA-tuned FIS also. The ANOM results are given in Fig. 9. The MRPI increases with increase in the current intensity, electrolyte concentration, and stick-out pressure. A scrutiny of response plots indicates that a proper combination of C-EC-SR and a suitable stick grit size is required to be employed for better MRPI in ECH. The MRPI is highest at the $3^{\text {rd }}$ levels of the current intensity $\left(\mathrm{C}_{3}\right)$, electrolyte concentration $\left(\mathrm{EC}_{3}\right)$, speed ratio $\left(\mathrm{SR}_{3}\right)$, stick-out pressure $\left(\mathrm{SOP}_{3}\right)$ and $2^{\text {nd }}$ level of stick grit size $\left(\mathrm{G}_{2}\right)$. The insignificant parameters viz. electrolyte flow rate and electrolyte inlet temperature can be set at their economic levels. The predicted optimal MRPI for combined optimization of PIR, $\mathrm{PICyl}$ and DIR in ECH using the GA-tuned FIS and ANFIS is given in Table 6. It is seen that the MRPI is quite high in both the approaches.

Table 5 Pooled ANOVA for MRPI

\begin{tabular}{|c|c|c|c|c|c|c|c|c|c|c|}
\hline \multirow{2}{*}{ Source } & \multicolumn{5}{|c|}{ GA-tuned FIS } & \multicolumn{5}{|c|}{ ANFIS } \\
\hline & SS & $\mathrm{DF}$ & MS & F ratio & $\%$ Cont & SS & $\mathrm{DF}$ & MS & F ratio & $\%$ Cont \\
\hline $\mathrm{C}$ & 0.101 & 2 & 0.050 & $57.83^{*}$ & 21.45 & 0.186 & 2 & 0.093 & $28.61^{*}$ & 26.67 \\
\hline $\mathrm{EC}$ & 0.084 & 2 & 0.042 & $48.46^{*}$ & 17.91 & 0.063 & 2 & 0.032 & $9.78^{*}$ & 8.48 \\
\hline SR & 0.023 & 2 & 0.011 & $13.13^{*}$ & 4.58 & 0.008 & (2) & Pooled & - & - \\
\hline $\mathrm{F}$ & 0.003 & (2) & Pooled & - & - & 0.003 & (2) & Pooled & - & - \\
\hline $\mathrm{T}$ & 0.001 & (2) & Pooled & - & - & 0.008 & (2) & Pooled & - & - \\
\hline SOP & 0.105 & 2 & 0.053 & $60.37 *$ & 22.41 & 0.103 & 2 & 0.051 & $15.82 *$ & 14.31 \\
\hline G & 0.030 & 2 & 0.015 & $16.99 *$ & 6.04 & 0.101 & 2 & 0.051 & $15.60^{*}$ & 14.11 \\
\hline $\mathrm{C}-\mathrm{EC}$ & 0.048 & 4 & 0.012 & $13.82 *$ & 9.68 & 0.035 & 4 & 0.009 & $2.71 *$ & 3.29 \\
\hline C-SR & 0.024 & 4 & 0.006 & $6.81 *$ & 4.38 & 0.041 & 4 & 0.010 & $3.12 *$ & 4.10 \\
\hline EC-SR & 0.043 & 4 & 0.011 & $12.45^{*}$ & 8.64 & 0.124 & 4 & 0.031 & $9.53 *$ & 16.48 \\
\hline Model & 0.458 & 22 & 0.021 & $23.90 *$ & 95.09 & 0.652 & 20 & 0.033 & $10.05^{*}$ & 87.44 \\
\hline e(pooled) & 0.003 & 4 & 0.001 & & 4.91 & 0.019 & 6 & 0.003 & & 12.56 \\
\hline Total & 0.462 & 26 & & & 100.00 & 0.672 & 26 & & & 100.00 \\
\hline
\end{tabular}

The Model F ratio of 23.90 and 10.05 imply that Models are significant at a $99.5 \%$ confidence level.

* Significant at $95 \%$ confidence level.

SS: Sum of square, DF: Degree of freedom, MS: Mean square, Cont: Contribution.

\section{Confirmation Experiments}

Once the optimal parametric setting is selected, the last step is to verify the improvements in process performance using the optimal process parametric settings. Table 6 gives the actual experimental results. It can be seen that PIR improved from $61.67 \%$ to $87.47 \%$, PICyl improved from $40.40 \%$ to $77.09 \%$ and DIR increased from $13.47(\mu \mathrm{m} / \mathrm{min})$ to $57.11(\mu \mathrm{m} / \mathrm{min})$. Also the actual MRPI results are in good close agreement with those predicted.

\section{Conclusions}

In this paper, an integrated strategy using the Taguchi matrix experimental design, analysis of variances, fuzzy inference system with two approaches: genetic algorithm tuning of FIS and ANFIS has been formulated to form a robust practical methodology for the multi-performance optimization of electro-chemical honing process. The strategy can be highly suitable for performance optimization of complex manufacturing processes that may 
involve several control variables with their parametric relationships defined vaguely. The technique may also be reformulated for improving the machining time for a given level of multi-performance of the process. The potential of the strategy has been demonstrated using a multi-performance optimization case study of ECH process. The predicted multi-response performance index of the GA-tuned FIS and ANFIS for ECH are quite high. Also the actual experimental results at optimal parametric settings arrived at using the approaches confirm feasibility of methodology for a wide range of processing conditions employed in ECH.

Table 6 Confirmation experiment results

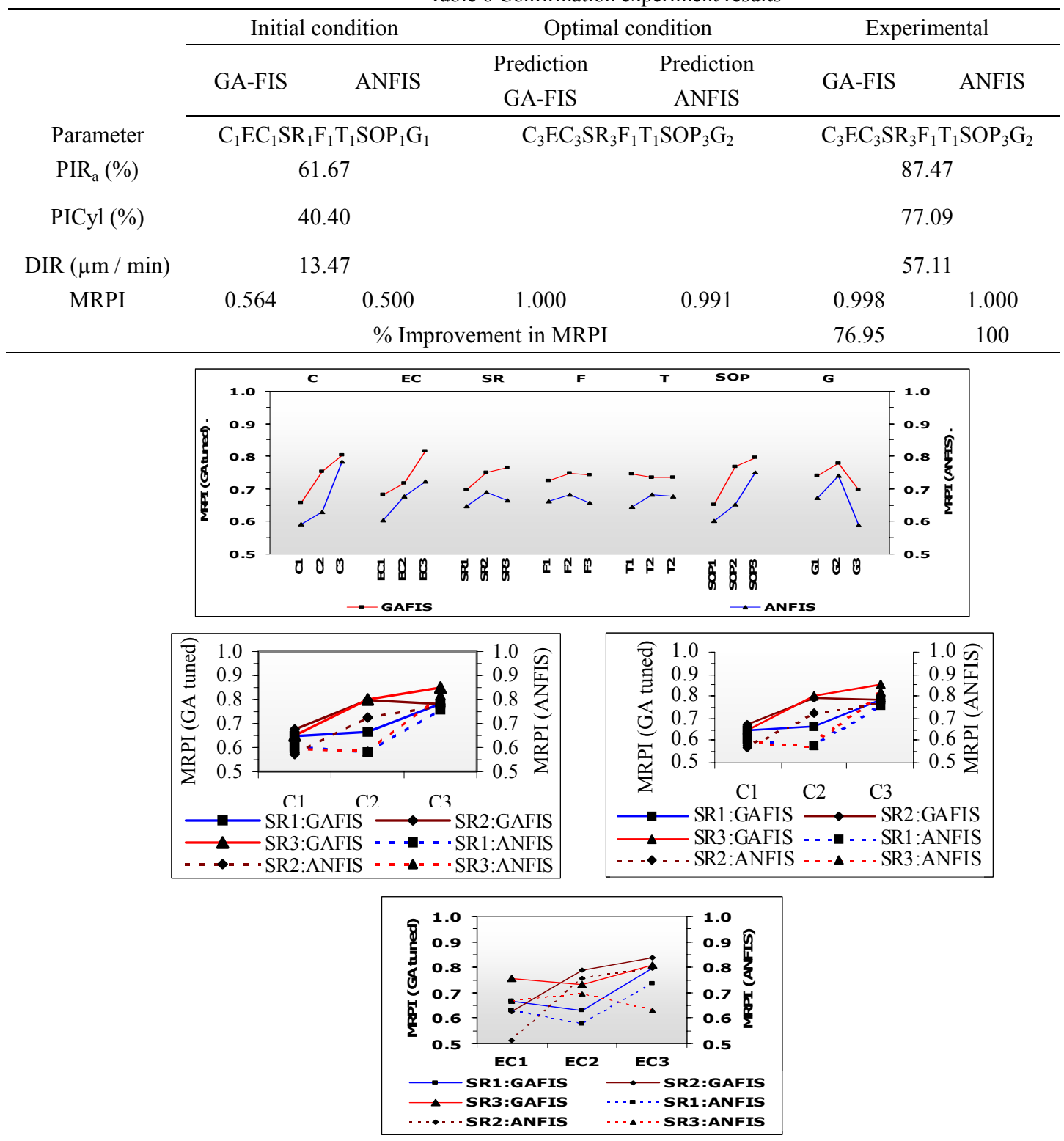

Fig. 10 Response plots

\section{Acknowledgements}

Author acknowledges with gratitude the guidance and critical reviews of his Ph.D. Thesis Supervisors, Prof. H.S. Shan and Dr. N.K. Jain of Indian Institute of Technology, Roorkee (India). His sincere thanks are also due to Mr. P.K. Jamwal, Sr. Lecturer, Mechanical Engineering Department, Engineering College, Kota (India) for his suggestions during FIS modeling and QC-T Unit of Bharat Heavy Electricals Limited, Hardwar (India) for the macro-geometrical measurements. 


\section{References}

(1) Dubey, A.K., Shan, H.S. and Jain, N.K., Analysis of Surface Roughness and Out-of-Roundness in Electro-Chemical Honing Process, Proceedings of the 1st International \& 22nd AIMTDR, IIT Roorkee, December 21-23 (2006), pp.887-892. Int. J. of Advanced Manufacturing Technology (2007), doi: 10.1007/s00170-007-1180-z.

(2) Dubey, A.K., Shan, H.S. and Jain, N.K., Precision Micro-finishing by Electro-Chemical Honing, Proceedings of the International Conference on Manufacturing Science and Technology' 2006, Melaka, August 28-30 (2006), pp.173-176. Int. J. of Manufacturing Technology and Management, Vol.17 (4) (2009), pp.364-372.

(3) Benedict, G.F., Nontraditional Manufacturing Processes, (1987), Marcel Dekker Inc.

(4) Dubey, A.K., Time Dependent Behavior of Electro-Chemical Honing, Int J Manufacturing Technology and Management (2008) (accepted paper id 1308).

(5) Randlett, E.A. (Jr.) and Ellis, M.P., Electrochemical Honing, ASTM, MR 68-815 (1968), pp. 1-11.

(6) Dubey, A.K., Multi-Response Optimization of Electro-Chemical Honing Process using Utility-Based Taguchi Approach, Int. J. of Advanced Manufacturing Technology (2008), doi: 10.1007/s00170-008-1525-2.

(7) Wang, K., Gelgele, H.L., Wang, Yi, Yuan, Q. and Fang, M., A Hybrid Intelligent Method for Modeling the EDM Process, Int. J. of Machine Tools and Manufacture, Vol.43 (2003), pp. 995-999.

(8) Srinivasu, D.S., Ramesh Babu, N. and Srinivasa, Y.G., Neuro-Genetic Approach for Automatic Selection of Process Parameters in Abrasive Water Jet Cutting Considering the Variation in Bore Diameter of Focusing Nozzle, Proceedings of the 21st AIMTDR, Vellore, India, December 20-22 (2004), pp. 887-893.

(9) Sen, M. and Shan, H.S., Optimal Selection of Machining Conditions in the Electro Jet Drilling Process using Hybrid NN-DF-GA Approach, Int. J. of Materials and Manufacturing Processes (2006).

(10) Dubey, A.K., A Hybrid Approach for Multi-Performance Optimization of the Electro-Chemical Honing Process, Int. J. of Advanced Manufacturing Technology (2008), doi: 10.1007/s00170-008-1422-8.

(11) Dubey, A.K., Multi-performance Modeling and Optimization Control Strategies for Electro-Chemical Honing: A Critical Evaluation, Int. J. of Advanced Manufacturing Technology (2008), doi: 10.1007/s00170-008-1477-6.

(12) Ostermark, R., A Hybrid Genetic Fuzzy Neural Network Algorithm Designed for Classification Problems Involving Several Groups, Fuzzy Set and Systems, Vol.114 (2000), pp.311-324.

(13) Cheng, C.B., Cheng, C.J. and Lee, E.S., Neuro-Fuzzy and Genetic Algorithm in Multiple Response Optimization, Computers and Mathematics with Applications- an International Journal, Vol.44 (2002), pp.1503-1514.

(14) Lu, D. and Antony, J., Optimization of Multiple Responses using a Fuzzy-Rule Based Inference System, Int. Journal of Prod. Research, Vol.40, No. 7 (2002), pp.1613-1625.

(15) Dubey, A.K., Experimental Investigations on Electro-Chemical Honing, Proc. IMechE Part B: J. of Engineering Manufacture, Vol. 222 (3) (2008), pp.413-426.

(16) Zadeh, L.A., Fuzzy Sets, Inf. Control, Vol. 8 (1965), pp.338-353.

(17) Zadeh, L.A., Fuzzy Sets and Applications, (1987), John Wiley and Sons, New York.

(18) Lin, C-T., Chung, I.F. and Huang, S-Y., Improvement of Machining Accuracy by Fuzzy Logic at Corner Parts of Wire-EDM, Fuzzy Sets and Systems, Vol.122 (2001), pp.499-511.

(19) Jang, J-S Roger, ANFIS: Adaptive Network-Based Fuzzy Inference System, IEEE Trans. on Systems, Man and Cybernetics, Vol.23, No.3 (1993), pp.665-685.

(20) Hayward, G. and Davidson, V., Fuzzy Logic Applications, Analyst (the royal Society of Chemistry Journal), Vol.128 (2003), pp.1304-1306. 
(21) Ross, T., Fuzzy Logic with Engineering Applications, (2004), John Wiley and Sons, New York.

(22) Herrera, F., Lozano, M. and Vergedgay, J.L., Tuning Fuzzy Logic Controller by Genetic Algorithms, International Journal of Approximate Reasoning, Vol. 12 (1995), pp.299-315.

(23) Nandi, A.K. and Pratihar, D.K., Automatic Design of Fuzzy Logic Controller using a Genetic Algorithm to Predict Power Requirements and Surface Finish in Grinding, Journal of Materials Processing Technology, Vol.148 (2004), pp.288-300.

(24) Hines, J. W., MATLAB Supplement to Fuzzy and Neural Approaches in Engineering, (1997), John Wiley and Sons, New York.

(25) Rajasekaran, S. and Pai, G.A.V., Neural Networks, Fuzzy Logic and Genetic Algorithms: Synthesis and Applications, (2003), Prentice-Hall of India Pvt. Ltd., New Delhi.

(26) Ross, P.J., Taguchi Techniques for Quality Engineering, (1998), McGraw-Hill Book Company, New York.

(27) Roy, R.K., A Primer on the Taguchi Method, (1990), Competitive Manufacturing Series, Van Nostrand Reinhold, New York. 